AperTO - Archivio Istituzionale Open Access dell'Università di Torino

\title{
Impact of Police Academy Training on Recruits' Integrity
}

\section{This is the author's manuscript}

Original Citation:

\section{Availability:}

This version is available http://hdl.handle.net/2318/1543355

since 2016-01-11T10:21:36Z

Published version:

DOI:10.1177/1098611115608322

Terms of use:

Open Access

Anyone can freely access the full text of works made available as "Open Access". Works made available under a Creative Commons license can be used according to the terms and conditions of said license. Use of all other works requires consent of the right holder (author or publisher) if not exempted from copyright protection by the applicable law. 
This is the author's final version of the contribution published as:

Blumberg, D. M.; Giromini, L.; Jacobson, L. B.. Impact of Police Academy Training on Recruits' Integrity. POLICE QUARTERLY. None pp: 1-24. DOI: $10.1177 / 1098611115608322$

The publisher's version is available at:

http://pqx.sagepub.com/cgi/doi/10.1177/1098611115608322

When citing, please refer to the published version.

Link to this full text:

http://hdl.handle.net/2318/1543355 


\title{
Impact of Police Academy Training on Recruits' Integrity
}

\begin{abstract}
Police integrity, or the lack thereof, is a frequent topic throughout media, academia, and all law enforcement organizations. The issue has been addressed on an individual and organizational level, but continues to raise as many questions as it answers. One argument is that police training causes declination in recruits' values, which eventually leads to officers acting in unethical ways. The present study examined the extent to which police academy training impacts recruits' self-reported integrity, which was measured at the beginning and end of academy training. Three different training formats $(n 1=143, n 2=87, n 3=27)$ were observed, social desirability was assessed to control for response bias, and self-reported emotional intelligence was measured as a potential moderator variable. Results indicated that participants started with significantly higher than average levels of integrity (with Cohen's $d$ values ranging from .56 to .83 ) and training had no significant impact on their integrity scores, even when corrected for social desirability. The results were not impacted by the length of training, preacademy level of emotional intelligence, or a variety of demographic variables. The study encourages law enforcement organizations to focus on ways to help their employees maintain high levels of ethical decision-making.
\end{abstract}

\section{Keywords:}

Police integrity, police academy training, occupational socialization, emotional intelligence, noble cause 


\section{Impact of Police Academy Training on Recruits' Integrity}

According to the National Institute of Justice (NIJ, 2012), “One of the biggest challenges to public trust and confidence in the police continues to be police integrity" (p. 4). Primarily, the impetus to study integrity grows out of the strong desire to decrease corruption in all its forms among law enforcement personnel. However, despite a persistent and vocal commitment from police administrators, political leaders, and community oversight committees to tackle the problem of corruption, there are nearly daily reminders of problems with the integrity of peace officers who make dishonest or corrupt decisions. While most agencies have well established procedures to handle corruption when it is discovered, it is believed that most corruption goes undetected (e.g. Klockars, Ivkovic, Harver, \& Haberfeld, 2000). And, unfortunately, there is still far too little known about how to prevent police corruption in the first place. One place to begin an examination of police integrity is to look at the possible impact of training on the integrity of police academy recruits.

But first, there have been two broad viewpoints on police integrity. These can be labeled an individual orientation, often referred to as the bad apple approach, and an organizational orientation (e.g. Caldero \& Crank, 2011; Dean, Bell, \& Lauchs, 2010; Heffernan, 1982; Klockars et al., 2006, 2004, 2000; Miller \& Braswell, 1992; Schafer \& Martinelli, 2008). The organizational approach looks to combat corruption by increasing organizational oversight and strengthening organizational commitment to ethical decision-making rather than focusing primarily on deficits in the character of individual peace officers. Researchers from this perspective believe that corruption can be curtailed at an organizational level by focusing on and improving the ways in which law enforcement agencies and their peace officers: recognize the 
seriousness of various offenses; understand how violations are disciplined; discourage personnel from maintaining the code of silence; and, generally promote ethical behavior (e.g. Klockars et al., 2000).

Providing an intriguing argument that the traditional organizational orientation to police corruption is insufficient, Caldero and Crank (2011) offer a more transactional perspective. They believe that some forms of corruption are due neither exclusively to the failings of individual officers nor to ineffective organizational conditions. Instead, they argue that some forms of corruption stem from moral dilemmas, which are routinely faced by peace officers. They contend that newly hired peace officers "tend to be exceptionally ethical" (p.62) and share the organization's "moral commitment to make the world a safer place to live" (p.31), which they label as the noble cause. The moral dilemmas stem from conflicts between pursuing the noble cause and upholding the letter of the law. When peace officers choose the former, it can result in the type of corruption that is referred to as noble-cause corruption, which occurs "when an officer breaks the law in order to achieve a good end" (p.31). Rather than due to greed, laziness, or antisocial tendencies, peace officers who commit this form of corruption (e.g. illegal searches and seizures, perjury, and even some forms of excessive force) continue to be motivated by a desire to rid their community of criminals. Nevertheless, this behavior is still, by any definition of corruption, wrong.

Although it is important to continue efforts to improve integrity at an organizational level, it would be a mistake to ignore the study of police integrity from an individual standpoint (e.g. Sellbom, Fischler, \& Ben-Porath, 2007; Heffernan, 1982). For example, it has been shown that education in ethics can improve individuals' level of moral reasoning and their ability to 
successfully navigate complex ethical issues (Prenzler, 2009). Presumably, the reverse also is true (i.e. certain training can lead to decreases in individuals' level of moral reasoning).

Research has demonstrated that individuals will experience, at various times in their life, revisions of their values and moral standards (Velasquez, 1998). One way in which these changes occur is through the socialization process associated with indoctrination into a new cultural milieu. Paramilitary training, such as during a law enforcement academy, has been shown to provide strong occupational socialization as cadets are groomed to become successful peace officers (Berg, 1990; Chappell \& Lanza-Kaduce, 2010; Haarr, 2001). ${ }^{1}$ This grooming can result in cadets altering their values to conform more closely to those of their training officers (Bennett, 1984) or resigning from the program rather than aligning their values with those of their academy classmates (Haarr, 2005).

Research on law enforcement training also suggests that the academy experience can have a deleterious impact on at least some cadets' level of personal integrity (Garner, 2005). Ford (2003) stated it in stark terms: "Recruits enter high-minded and service oriented. They may be at their ethical zenith" (p. 85). This is attributed to the impact of some of the content of the training, whereby recruits are inundated with explicit stories and implicit messages about unethical behavior and attitudes by veteran officers (Chappell \& Lanza-Kaduce, 2010; Ford, 2003). Some suggest that an overemphasis on the dangerousness of police work during academy training can lead to an erosion of cadets' pre-academy level of integrity; "the perception of danger may be the catalyst that triggers value change... Danger may be the justification for the unethical and the illegal" (Ford, 2003, p. 104). Specifically, byproducts of the training may be: 1) to foster "us versus them" attitudes; 2) to instill strong bonds among cadets in order to rely on each other to stay out of trouble or to avoid punishment; 3) to learn that there is a difference 
between the letter of the law and the spirit of the law (i.e. peace officers often have to use discretion); and, 4) to understand that morality is sometimes situational or relative, e.g. peace officers are legally permitted to lie to or deceive a suspect (Chappell \& Lanza-Kaduce, 2010).

Regardless, it is widely accepted that the vast majority of peace officers, including those who later behave in self-serving and/or corrupt ways, do not begin their law enforcement careers with deficits in integrity. Law enforcement agencies specifically seek to hire job applicants who have been determined through an extensive background investigation process to possess good moral character. For example, the first of ten dimensions listed in California's manual for background investigators (CA POST, 2013) is integrity. Agencies are explicitly directed to hire only those job applicants who have demonstrated "high standards of personal conduct. (Integrity) consists of attributes such as honesty, impartiality, trustworthiness, and abiding by laws, regulations, and procedures" (CA POST, 2013, p. 2-4). The hiring process even includes the administration of a specific truth/honesty assessment (e.g. polygraph or computer voice stress analysis), which further weeds out applicants who are not completely truthful during the hiring process.

Moreover, applicants for law enforcement positions will not be hired prior to successful completion of a psychological evaluation. Integrity-Ethics is one of the psychological screening dimensions for which applicants are evaluated by a qualified mental health professional (e.g. CA POST, 2004). Research continues to address ways in which these pre-hire psychological evaluations can better assess job applicants' integrity as well as to identify which applicants may be more likely to engage in future unethical or corrupt behavior (e.g. Sellbom, Fischler, \& BenPorath, 2007; Weiss, Vivian, Weiss, Davis, \& Rostow, 2013). Thus, there are few jobs for which 
as much scrutiny is paid to ensure that job applicants have acceptable levels of personal integrity before they are hired.

\section{Academy Training and Integrity}

Academy training curricula are mandated by state commissions on Peace Officer Standards and Training (POST). ${ }^{2}$ Research has demonstrated the importance of this training to instill recruits with necessary occupational skills as well as with essential professional socialization (e.g. Bauer \& Erdogan, 2010; Chappell \& Lanza-Kaduce, 2010; Conti, 2011; Conti \& Nolan, 2005). However, over forty years ago, Teasley and Wright (1973) reported that police academy training impacted recruits' attitudes, particularly increasing their dogmatism scores (p. 246). More recent discussions have focused on the ways that law enforcement training in its present form contributes to avoidable deaths in the field (Stoughton, 2014) and should be improved to reduce racial bias (e.g. Sadler, Correll, Park, \& Judd, 2012) and excessive force (e.g. Klinger, 2012). Such improvements in training curriculum should also focus more on the numerous inherent stressors associated with the job—-beyond dangerousness — and teach recruits specific strategies to cope with stress and maintain good health after the academy (e.g. Papazoglou \& Anderson, 2014).

With all the attention paid to the content of police training and despite the cautions mentioned above, there has been a lack of research on the direct effects of academy training on recruits' integrity. ${ }^{3}$ Conversely, integrity research with other populations has proven quite informative (e.g. Miller \& Schlenker, 2011; Schlenker, 2011; Schlenker, 2008; Simmons et al., 2014). For example, results of studies using the Integrity Scale (Schlenker, 2008) have provided information about respondents' level of principled versus expedient beliefs. Among many other outcomes, these results determined that integrity was related to "less rationalization of illegal and 
immoral behavior," (Schlenker, 2008, p. 1118). In numerous studies using the instrument, scores were able to provide "a distinctive individual difference variable that is useful in predicting the violation of moral rules" (Ibid.). While it has not been used with a law enforcement population, it was used in a study with West Point cadets (Graves et al., 2010).

\section{Possible Role of Emotional Intelligence}

Emotional intelligence has received considerable and growing attention in academic and organizational settings (e.g. Day, \& Carroll, 2004; Gaudine, \& Thorne, 2001; Lopes, Cote, \& Salovey, 2006; Salovey, \& Grewal, 2005; Schutte, Schettpelz, \& Malouff, 2001). The theory states that "a person's ability to accurately perceive, use, understand, and regulate emotions may help to prevent involvement in potentially harmful behaviors" (Brackett, Lopes, Ivcevic, Mayer, \& Salovey, 2004, p. 187). Some of the research on emotional intelligence (EI) is particularly germane to the present study in that it focuses on the role that EI plays in ethical decisionmaking, particularly in the workplace. Research has found that employees with high EI are "less likely to perceive unethical behaviors as (a) necessary tool for gaining a competitive advantage," whereas "low EI individuals may actually feel justified in their use of unethical tactics" (Mesmer-Magnus, Viswesvaran, Deshpande, \& Joseph, 2010, p. 42). These authors found that because high EI employees are able to recognize their own and others' emotions, they are more adept than low EI employees at perceiving a variety of contextual cues before deciding whether or not to behave unethically (Mesmer-Magnus et al., 2010; Mesmer-Magnus, Viswesvaran, Joseph, \& Deshpande, 2008). Similarly, Carmeli and Josman (2006) found that EI was positively related to better employee work outcomes, including the organizational citizenship behaviors of altruism and compliance (p. 412). 
Although there have been efforts to train peace officers how to better manage their emotional reactions (e.g. Cherniss, 2000), insufficient attention has been directed to the role of EI in law enforcement. One study discussed how EI positively contributes to peace officer safety (Manzella \& West, 2003). Dar, Alam, and Lone (2011) found a positive relationship between psychological wellbeing and emotional intelligence in police officers in India. Smith (2010), examining veteran police officers, reported a correlation between EI and moral development (p. 114). And, a recent study (Aremu, Pakes, \& Johnston, 2011) showed "the usefulness of EI in improving integrity-based policing” (p. 204) among Nigerian police officers. Nevertheless, the relationship between EI and integrity among law enforcement personnel has not received much attention.

\section{The Current Study}

The current study sought to investigate whether police academy training would have any impact on the overall integrity levels of the recruits. Specifically, we collected longitudinal data and tested whether the recruits' integrity levels before and after undergoing police academy training would show a significant difference. Additionally, data were gathered from three different peace officer training academies. Although sample size varied, this at least provided an opportunity to see whether or not there were any differences or trends associated changes in integrity levels among participants from the different academies. We also investigated whether baseline levels of EI would moderate the effects of academy training on the recruits' integrity. More broadly, thus, this study aimed to help professionals in the field to better understand what impact, if any, police academy training has on recruits' level of personal integrity. 


\section{Method}

Recruits from three law enforcement training academies in a large, metropolitan area in southern California contributed the data for the current study. Because each academy represents a different training format, the study can be considered to involve three independent populations. Academy 1 is a regional training academy in which recruits participate on a full-time basis (i.e., Monday through Friday) for six months. Participants from this academy already have been hired by a law enforcement agency; they have received an extensive background investigation and passed numerous pre-hire tests and interviews. ${ }^{4}$ These recruits will begin field training as sworn peace officers upon successful completion of academy training. Academy 2 is a detentions training academy in which recruits participate on a full-time basis (Monday through Friday) for sixteen weeks. All of these recruits have already been hired by a law enforcement agency; they receive the same pre-hire background investigation, tests, and interviews as recruits in Academy 1. Upon successful completion of academy training, these recruits will begin field training as a Detentions/Court Services Deputy Sheriff. Neither of these academies is "live-in" (i.e., recruits go home after training finishes each day).

Academy 3 is an accredited extended format police academy, which provides a curriculum similar to Academy 1 in that it, too, conforms to the training requirements established by the state's Commission on Peace Officer Standards and Training. However, none of these recruits has been hired yet by a law enforcement agency. Potential recruits go through an application process prior to being accepted to the academy. Training occurs on a part-time basis (i.e. Tuesday through Friday evenings and Saturdays) for twelve months. After successful completion of academy training, most of these recruits seek employment as sworn peace officers with any law enforcement agency, which may be hiring. 
Although the content of the training in Academy 2 was different than that of Academy 1 and Academy 3, this Academy was included in the present study to provide a way to assess the possible impact of full-time versus part-time academy attendance as well as the possible impact of already hired versus not-hired recruits. In this way, the potential impact of differing levels of immersion could be assessed.

Three self-report instruments were administered prior to (T1) and following (T2) academy training. These instruments measured integrity, EI, and social desirability (see below). A brief history form was also completed at T1 to collect information about possible mediating effects of demographic variables.

\section{Participants}

At T1, the sample was comprised of 309 participants. Of these participants, 168 came from Academy 1, 110 attended Academy 2, and 31 were from Academy 3. Participants' ages ranged from 19 to $59(M=27.9, S D=6.8) .{ }^{5}$ T1 included 235 males $(76 \%)$ and 74 females (24\%). Participants's self-reported race/ethnicity was: White/Non-Hispanic 54.7\%;

Hispanic/Latino/a 19.1\%; Multiracial 11.0\%; Asian 5.8\%; Black/African-American 3.9\%; and, the remaining 5.5\% were scattered among Hawaiian/Pacific Islander, Native American, Middle Eastern, and East Indian.

Over half of the participants $(61.2 \%)$ at T1 had college degrees. One hundred-twentyfive participants (40.5\%) earned a Bachelor's degree, while 43 (13.9\%) had Associate's degrees, and $21(6.8 \%)$ completed a graduate degree. Ninety-six participants $(31.1 \%)$ reported some college experience. Only $22(7.1 \%)$ had just a high school diploma or equivalent. Two participants (.6\%) provided no information about their education level. 
Many participants at T1 had some related experience. One-hundred-eight participants $(35 \%)$ reported having prior public safety experience and/or training. Seventy-six participants (24.6\%) were military veterans. Except for five of the veterans who failed to specify, all received honorable discharges from military service.

At T2, 257 participants $(83.2 \%$ ) remained in the study. Of the 52 participants (ages 21 to $59[M=31.2, S D=8.4])^{6}$ for whom T2 data were not collected, only one opted out of the study. Thirteen (25\%) were terminated from their training academy. Twenty-four (46.2\%) resigned during training. Five participants $(9.6 \%)$ received injuries during academy training, were not allowed to complete training, and, therefore, were not available for T2 data collection. The reason for attrition of nine $(17.3 \%)$ of the 52 participants who did not complete their training was unspecified by the academy staff who provided this information.

Attrition analyses revealed that the participants who remained at T2 versus those who dropped out did not significantly differ for gender, ${ }^{7} \mathrm{Phi}=.05, p=.36$, race/ethnicity, ${ }^{8}$ chi(4) $=$ 2.94, $p=.57$, education, $U=6595.5, p=.95$, prior public safety experience and/or training, $P h i$ $=.04, p=.49$, or prior military service, $P h i=.11, p=.07$. Similarly, the two groups did not differ in their T1 scores of integrity, $t(307)=.94, p=.35$, emotional intelligence, $t(307)=1.41, p$ $=.16$, or social desirability, $t(307)=1.17, p=.24$, as measured by the self-report instruments described below. However, the participants who dropped out were significantly older than those who remained at $\mathrm{T} 2, t(58.1)=3.28, p<.01, d=.69 .{ }^{9}$ In fact, the group who remained at $\mathrm{T} 2 \mathrm{had}$ a mean age of $27.2(S D=5.2)$, while those who dropped out had a mean age of $31.2(S D=8.4)$. Albeit statistically significant, it should be noted that the difference in age between the two groups consisted of about only four years, which in adulthood is very unlikely to have a meaningful impact on the integrity scores. Indeed, the correlation between age and our integrity 
measure (see below) was -.07, $p=.21$ at $\mathrm{T} 1$ and $-.04, p=.50$ at T2. Thus, it is very unlikely, virtually impossible, that this small difference in age had any impact on the results of our study.

\section{Procedure}

Letters of support for and complete cooperation with the procedures of the study were obtained from academy directors as well as from the Police Chiefs and county Sheriff whose recruits volunteered to participate in this research. Additionally, approval for the study was obtained and renewed on an annual basis from the Institutional Review Board at the primary investigator's university.

Participants were recruited from three consecutive classes of Academy 1 and Academy 2 as well as from one class at Academy 3. All recruits from these classes were eligible to participate (i.e. there were no exclusion criteria). No compensation for participation was offered.

T1 data collection occurred during pre-academy orientations in conference rooms either at the cooperating law enforcement agencies (Academy 1 and Academy 2) or at Academy 3. The purpose of the research, the time involved, and the procedures utilized were explained to all recruits in attendance. Those agreeing to volunteer were handed Informed Consent forms to read and sign. ${ }^{10}$ After turning in the signed consent form, recruits were handed the packet of instruments to complete. The time involved during T1 was approximately thirty minutes.

T2 data collection occurred within a few days prior to academy graduation in conference rooms at the academies. Informed consent was again obtained from participants, all but one of whom agreed to continue participation in the study. Recruits were handed the packet of instruments to complete, which took approximately fifteen minutes, because the demographic form was administered only at $\mathrm{T} 1$. 


\section{Measures}

Participants were asked to fill out three self-report instruments related, respectively, to integrity, social desirability, and emotional intelligence. Specifically, they were administered the following self-report questionnaires:

Integrity Scale (Schlenker, 2008). The Integrity Scale is an 18 item self-report instrument developed by Dr. Schlenker to measure "the inherent value of principled conduct, the steadfast commitment to principles despite temptations or costs, and the unwillingness to rationalize unprincipled behavior" (Schlenker, 2008, pp. 1084-85). Participants are asked to rate each item on a 5-point Likert scale ( 1 = "strongly disagree"; 5 = "strongly agree"), and a total score is given by summating the items. The higher the total score, the greater the (self-reported) commitment to ethical principles.

Some empirical data support the validity of the Integrity Scale. Miller and Schlenker (2007), for example, showed significant associations with measures of commitment to moral identity, and Schlenker, Weigold, and Schlenker (2008) reported that participants with higher scores on the Integrity Scale spontaneously described their heroes as more honest and principled. As for the reliability, Johnson and Schlenker (2007), reported Cronbach's $\alpha$ values ranging from .84 to .90 , and test-retest correlations ranging from $r=.72$ to $r=.82$. In the current study, Cronbach's $\alpha$ was .77 at T1, and .81 at T2, thus confirming the adequate internal consistency of the scale. $^{11}$

\section{Balanced Inventory of Desirable Responding (BIDR; Paulhus, 1991, 1999). The}

BIDR includes 40 items on 5-point Likert scale, which are then combined to produce two dimensions of socially desirable responding: Self-Deceptive Enhancement (SDE) and Impression Management (IM). High scores on the SDE subscale (20 items) reflect a tendency towards 
overly positive self-presentation; high scores on the IM subscale (20 items) reflect a responding style that is typical of individuals who want to look good to the person who reads the results of the questionnaire. The total BIDR score (40 items), thus, provides a global measure of socially desirable responding attitude. Among other uses, the BIDR is often utilized along with other instruments in order to statistically control their scores for the presence of social desirability (Hirschfeld et al., 2000; Vispoel \& Forte Fast, 2000). In the current study we also used the BIDR as a means for controlling for socially desirable responding.

Various data support the construct validity of the BIDR (Paulhus, 1991, 1999, 2002;

Vispoel \& Han Yi Kim, 2014), as well as its reliability (e.g., Paulhus, 1999). In the current study, alphas were .78 (IM), .73 (SDE), and .85 (total BIDR score) at T1, and .77 (IM), .73 (SDE), and .84 (total BIDR score) at T2. ${ }^{12}$

\section{Self-Rated Emotion Intelligence Scale (SREIS; Brackett, Rivers, Shiffman, Lerner,}

\& Salovey, 2006). The SREIS is a 19 item self-report instrument measuring emotional intelligence. It was developed by Brackett et al. (2006) to represent the contents of the MayerSalovey-Caruso Emotional Intelligence Test (MSCEIT, Mayer, Salovey \& Caruso, 2002), a comprehensive performance test of emotional intelligence. Though the SREIS is relatively new, initial research supports its validity and reliability (Brackett et al., 2006). In the current study, the internal consistency of the scale was adequate too, with a Cronbach's $\alpha$ of .74 at T1, and .77 at T2. ${ }^{13}$

\section{Data Analysis}

The main purpose of the current study was to test whether the Integrity Scale scores at T2 were significantly different from those at T1. To do so, we tested a series of paired t-test 
statistics. Each sample was considered separately from the other two, because - as noted above each academy in fact represents a different training model.

Next, we tested whether the recruits' levels of EI before the beginning of the training affected the effects that this training had on their integrity scores. This was accomplished by testing a series of Repeated Measures, Within-Subject ANOVAs, with Time (T1 vs. T2) as within-subject factor, EI at T1 as covariate, and the Integrity Scale scores as dependent variables.

Social Desirability Adjusted - Integrity Scores. It is well known that social desirability may play a role in responding to a self-report instrument, and even more so when the self-report instrument under investigation measures a highly desirable characteristic such as integrity. To take this issue into account, in addition to considering the raw Integrity Scale score, we also estimated what each Integrity Scale score would look like after adjusting for the score obtained by that person on the BIDR scale. In other words, we predicted what each participant's integrity score would look like if his or her BIDR scale was controlled for and held constant at its mean value. To do so, we followed a three-step procedure (which was used separately for the data at $\mathrm{T} 1$ and the data at $\mathrm{T} 2$ ).

First, we tested a series of linear regression models, using the total scores of the BIDR scale to predict the mean scores of the Integrity Scale. Next, we saved the parameters (i.e., regression coefficients and intercepts) of the resultant regression models and used them to estimate the expected Integrity Scale score of each participant, based on his or her BIDR score. Lastly, we calculated the difference between the observed and the expected (based on social desirability) Integrity Scale scores and added these residuals to the mean value of the Integrity Scale score. What results from this procedure is a measure that shows what a participant's Integrity Scale score would look like if his or her BIDR scale (i.e., social desirability; SD) was 
controlled for and held constant at its mean value. For the sake of readability, we named this measure "SD adjusted - Integrity score." All statistical analyses described above were first tested using the raw Integrity Scale scores and then calculated again using the "SD adjusted - Integrity scores."

\section{Results}

Descriptive statistics relevant to the current study are shown in Table 1. At T1, the mean raw scores for the Integrity Scales were $73.4(S D=6.8)$ within academy $1,72.0(S D=7.9)$ within academy 2 , and $71.4(S D=6.1)$ within academy 3 . These values are notably higher than those observed by Schlenker (2011) in his Integrity Scale development study, where the mean value produced by a large student sample of 1341 respondents was $66.1(S D=9.6)$. Statistically speaking, these differences are highly significant, all p's<.0005, with Cohen's $d$ values ranging from .56 (academy 3 ) to .83 (academy 1), indicative of medium to large effect sizes (Cohen, 1988).

Within the academy 3 sample, the difference between integrity scores at T1 and T2 was nonsignificant both for the raw scores, $t(26)=1.33, p=.19, d=.26$ and for the social desirability - adjusted scores, $t(26)=1.55, p=.13, d=.30$. A similar pattern was also observed within the Academy 2 sample, with nonsignificant results for the both raw, $t(86)=.45, p=.65, d=.05$, and the social desirability - adjusted scores, $t(86)=.33, p=.74, d=.04$. Conversely, within the Academy 1 sample, the integrity scores at T2 were lower than those at T1, with significant differences when looking at the raw scores, $t(142)=2.22, p=.03, d=.19$, and marginally significant when looking at the social desirability - adjusted scores, $t(142)=1.91, p=.06, d=$ .16. It should be noted, however, that in all cases the effect size was rather small, with none of differences exceeding one third of standard deviation. 
To test whether the initial levels of emotional intelligence (i.e., EI at T1) would moderate the impact that undergoing police academy training may have on the Integrity Scale scores, we then tested a series of Repeated Measures, Within-Subject ANCOVAs, with Time (T1 vs. T2) as within-subject factor, EI at T1 as covariate, and the Integrity Scale scores as dependent variable. In all cases, the interaction effect Time by EI was nonsignificant (see Table 2 for details), thus indicating that the initial levels of EI of the respondents do not affect the impact that the training had on the attendees' integrity scores.

Lastly, we also explored whether any demographic variables had some impact on our findings. To do so, we tested a series of Repeated Measures, Within-Subject ANCOVAs, with Time (T1 vs. T2) as within-subject factor, the integrity scores as dependent variables, and each of the demographic variables under investigation as between-subject factor (for categorical variables, such as gender or ethnicity) or covariate (for continuous variables, such as age). After applying Bonferroni's correction for multiple statistical tests, none of these analyses produced significant results.

\section{Additional Analyses}

The findings introduced above indicate that the academy training undertaken by the recruits had none or only modest impact on their integrity levels. In fact, only the Academy 1 group showed statistically significant differences between the integrity scores at T1 and T2, and the effect size was rather small $(d \leq .19)$. No significant differences were found within the Academy 2 and Academy 3 samples.

It should be pointed out, however, that with classic null-hypothesis significance tests (NHSTs), finding a nonsignificant result does not provide support for the null hypothesis (H0), but only adds evidence that H0 cannot be rejected (Altman \& Bland, 1995). Said differently, 
finding that training did not significantly affect the participants' scores on the Integrity Scale does not demonstrate that undergoing such academy training does not affect integrity (i.e., H0); it only fails to demonstrate the alternative hypothesis that the training does affect integrity.

Thus, wanting to more directly test the null hypothesis that police academy training did not influence the participants' levels of integrity, we undertook additional analyses. Specifically, we implemented Bayesian procedures (see Rouder et al., 2009) and used JZS Bayes Factor (Equation 1) to estimate the relative posterior probability of the null and alternative hypotheses, given the data, i.e., Pr.(H0 | data) / Pr.(H1 | data). This odds ratio can be interpreted using Jeffreys (1961) criteria, according to which values greater than 3 are to be considered as "some evidence," values greater than 10 are to be considered as "strong evidence," and values greater than 30 are to be considered as "very strong evidence" for the null over the alternative. Conversely, values lower than .33 are to be considered as "some evidence," values lower than .10 are to be considered as "strong evidence," and values lower than .03 are to be considered as "very strong evidence" for the alternative over the null.

The results of these additional analyses are reported in Table 3. Briefly, they indicate that: 1) within the Academy 3 sample, the null is about 2 to 3 times more probable than the alternative, given the data; 2) within the Academy 1 sample, the null is about as probable as the alternative when using the raw integrity scores, and about 2 times more probable than the alternative when using the social desirability - adjusted integrity scores (precisely, the null is 1.4 times more probable than the alternative when using the raw integrity scores, and 2.5 more probable when using the social desirability - adjusted integrity scores); 3) within the Academy 2 sample, the null is about 11 times more probable than the alternative, given the data. According to Jeffreys' (1961) characterization of the odds ratio values, hence, one may conclude that there 
is some limited evidence for the null within the Academy 3 sample, and there is strong evidence for the null within the Academy 2 sample. Conversely, because of a JZS B lower than 3 in absolute value, there is not enough information to make any conclusions concerning the Academy 1 sample.

Did the Integrity Scores Change at All? Taken together, the results of the statistical analyses reported above indicate that completion of peace officer training academy did not significantly affect the central tendency values of the cadets' integrity scores. However, a legitimate question, at this point, would be whether or not these integrity scores changed at all rather than simply if they did not change in a consistent way. Said differently, one might contend that the reason why we did not observe any consistent changes in our study (i.e., consistent increase or consistent decrease from $\mathrm{T} 1$ to $\mathrm{T} 2$ ) is that the test-retest interval under investigation was too short to produce any notable changes.

To investigate this interesting, alternative explanation, we ran additional analyses aimed at inspecting whether any notable changes occurred within any of our respondents. Consistent with Cohen (1988), as well as with the literature on personality assessment (e.g., Greene, 2000), we defined differences of half a standard deviation, or 5 T-points, to be "notable" differences in Integrity Scale scores from T1 to T2. As shown in Table 4, a relatively high percentage of participants in each of the Academies (i.e., $18.5 \%$ to $40.7 \%$ ) did show some notable changes in their integrity scores. These changes were simply not consistently in the same direction (i.e., about half increased and about half decreased). Taken together, thus, these findings rule out the hypothesis that the time range to potentially detect any notable differences in integrity scores was too short. 


\section{Discussion}

Police corruption has enormous costs for society and investigating underlying, psychological mechanisms is fundamental to its understanding and prevention. Because peace officers typically do not begin their careers with deficits in integrity, we wanted to investigate whether recruits' integrity scores would change following completion of a peace officer training academy. Results from three law enforcement academies, for a total $N$ of 257 individuals $(n 1=$ $143, n 2=87, n 3=27$ ), suggested that undergoing police academy training has minimal or no impact on the recruits' levels of self-reported integrity.

At the beginning of their training, recruits included in our study had a mean integrity score notably higher than the average score produced by a large sample of volunteer students described by Schenkler (2011). ${ }^{14}$ This finding is consistent with the idea that at the beginning of their careers, recruits tend to be highly principled and service oriented, and that low-integrity is not a typical characteristic of individuals who are permitted to receive law enforcement training. Although some caution should be warranted due to the self-report nature of the present data, this points to the strength and relative success of police hiring standards and practices (e.g. Blumberg, Griffin, \& Jones, 2014).

At the same time, our study does not support the hypothesis that the academy experience has a bad influence on recruits' integrity, as a consequence of exposure to stories of unethical behavior and attitudes by older police officers (Chappell \& Lanza-Kaduce, 2010; Ford, 2003; Garner, 2005). In fact, regardless of whether the training lasted sixteen weeks (academy 2), six months (academy 1) or one year (academy 3), the average recruit's integrity did not change after completing the training, and the integrity scores at T1 and T2 were strikingly similar, virtually 
identical. This conclusion is also supported by Bayesian analyses conducted using Rouder et al.'s (2009) method to investigate the null hypothesis.

This is particularly noteworthy when comparing Academy 1 and Academy 3 in that the curriculum from those academies is quite comparable. Recruits who attended Academy 3 maintained their current jobs and attended training on a part-time basis for one year; they can be considered to have had a far less immersive law enforcement socialization process. Moreover, these recruits have not yet been hired to work as peace officers after completion of training. Conversely, recruits from Academy 1 were fully immersed in the socialization process even before the start of the academy through the extensive hiring process and pre-academy orientations. They have been hired, purchased uniforms and equipment, and know that they will be sworn in as peace officers after successful completion of academy training. If training was to impact recruits' integrity, it would be expected to do so following the academy with the more intense socialization process.

It is also significant that the results of our study cannot be explained by social desirability and were not moderated by differences in emotional intelligence (EI). Indeed, because integrity self-rating scores may suffer from social desirability effects, we statistically manipulated the scores of the Integrity Scale so as to remove the variance associated with social desirability, and found that the results did not change. The social desirability adjusted - integrity scores at T1 and T2 were highly similar, virtually identical. Along the same line, we also wanted to investigate whether the T1 scores of EI would moderate the impact that undergoing academy training would have on the recruits' integrity scores. Once again, we found that regardless of the EI scores at the beginning of the training, the $\mathrm{T} 2$ integrity scores of the recruits were markedly similar to those at T1. 
EI has been consistently shown to impact a variety of behaviors. For example, EI is positively related to higher quality relationships with friends (Lopes et al., 2004), increased prosocial behavior (Charbonneau \& Nicol, 2002), and healthier life decisions (Brackett et al., 2004). Likewise, lower EI, particularly in males, was found to correlate with negative life outcomes, including involvement in deviant behaviors (Brackett, Mayer, \& Warner, 2004, p. 1398). The present results suggest that despite EI's affect on behavior, one's level of EI may not be responsible for impacting potential changes in one's ethical principles, which could occur as a result of intense socialization into a new cultural milieu.

Lastly, it should be noted that although, on one hand, the academy training we investigated did not decrease the integrity scores of our participants, on the other hand, this training also did not lead to increases in participants' self-rated integrity. Although beginning with higher scores on the Integrity Scale than previously reported samples, participants in this study could have reported even higher levels of principled beliefs upon completion of academy training. To facilitate the goal of sending well-trained and highly principled peace officers into the field after academy training, it may be prudent to explore methods to improve the ways in which integrity and, more specifically, ethical decision-making are taught, modeled, and practiced during the academy. This should include attention to noble cause corruption (Caldero \& Crank, 2011), which would not necessarily result from officers abandoning their integrity. Such behavior derives from moral dilemmas in which officers may continue to believe that they are righteously acting with high integrity. Therefore, training should be modified to explicitly address these moral dilemmas with clear guidelines about acceptable behavior in the field as well as unambiguous consequences for violations of approved policy and procedure. 


\section{Limitations}

Various limitations, however, should be kept in mind while interpreting the results of this study. First and most evident, we used self-report instruments which may obviously suffer from social desirability effects, along with other problems (such as poor self-awareness, individual variability in interpreting the items, etc.). Though we tried to statistically manipulate our data so as to take into account and remove the effects of social desirability, it would be important to replicate this study by including additional instruments, such as performance and/or outcome measures. In this regard, although it is a valid and reliable instrument, the Integrity Scale has not been used previously with a law enforcement sample. Future efforts might consider developing a law enforcement-specific integrity assessment instrument.

Second, the sample sizes of the three academies under investigation (especially that of academy 3) were relatively small, which admittedly limits the generalizability of our findings and warrants caution with respect to the role that different trainings may have on different cadets. Third, future studies might try to assess with additional psychological tools (e.g. MMPI-2, PAI) whether any specific psychological traits moderate the impact that academy training may have on certain recruits' level of integrity. In fact, it would be important to know whether any training would be more adequate and/or suitable for any given individuals, based on their personality characteristics, so as to enhance integrity.

Fourth, this study only focuses on the effects that undergoing academy training may have on the recruits' self-reported integrity and does not investigate whether the 'new' peace officers actually act with integrity. Future follow-ups of the current investigation might provide information that is more conclusive, with respect to the long-term impact that police academy training has on integrity as the recruits leave the academy and embark on field training. 


\section{Final Thoughts}

Prior research has looked at the extent to which recruits' performance during academy training correlates with their behavior in the field (e.g. Caro, 2011; Henson, Reyns, Klahm, \& Frank, 2010; White, 2008). Results have been quite mixed, but tend to highlight deficiencies in training vis-à-vis competent performance in the field after training. This makes intuitive sense and seems to parallel similar concerns in other fields when recent graduates hit the workforce (e.g. Bolander, Bonney, \& Satornino, 2014). In most of these discussions, the emphasis is on the technical, occupational skills necessary to competently perform one's job and how a new hire can best learn them (i.e. formal education, on-the-job training, or a combination of both).

In addition to mastering an immense amount of occupational skills (technical and interpersonal), competent police work requires a high level of personal character. The present study showed that newly hired peace officers (Academy 1 and Academy 2) begin and end academy training with high levels of self-reported integrity. Also, the study showed that individuals seeking future employment as peace officers who pay for their own law enforcement training (Academy 3) maintained high starting levels of self-reported integrity at the end of their twelve month academy. These findings should provide some measure of confidence to police academy training administrators and staff, despite concerns raised by earlier research (e.g. Ford, 2003; Garner, 2005). At the same time, the present results should cause police administrators to reconsider the extent to which field training and advanced officer training adequately instill and perpetuate organizational values of integrity and unwavering ethical decision-making.

Academic efforts to instill values and improve integrity have shown promise (e.g. Curtis, Gouldthorp, Thomas, O’brien, \& Correia, 2013). Similar attempts should be made to develop and implement police academy curriculum designed to teach recruits how to maintain their high 
pre-academy levels of integrity throughout training and into the field. Faced with numerous challenges to their principled values and confronted fairly regularly with a variety of moral dilemmas, peace officers would benefit from a strong organizational commitment to help them maintain their integrity. These efforts should expand beyond integrity to include related topics, including spiritual survival (Friedman, 2005), general wellness, emotional competency, and implicit bias. While continuing efforts will be made to curtail corruption, which is perpetrated by a small percentage of employees, at least as much attention should be spent working to keep the majority of highly ethical peace officers resolute in their commitment to the noble cause. 


\section{Notes}

1. The terms cadet and recruit are used synonymously.

2. Readers are referred to an excellent review of contemporary police training by Berlin (2013).

3. This is contrasted with numerous integrity studies of incumbent police officers and law enforcement agencies (see Gamarra, 2012 for a recent review).

4. Based on space availability, a few places may be filled by "open enrollees" (i.e. recruits who self-sponsor and hope to be hired by a law enforcement agency upon completion of academy training).

5. Thirteen records were missing age information.

6. One record was missing age information.

7. Two records were missing gender information.

8. To avoid low numbers in multiple cells, race was classified as follow: Asian; Black; Hispanic; White; Other. Also, it should be noted that 54 records were missing ethnicity information.

9. Because homoscedasticity could not be assumed, Welch-Satterthwaite method was used to adjust degrees of freedom.

10. At most, one or two recruits per class did not agree to participate in the study.

11. These statistics refer to the entire, combined sample. Similar results were observed when looking at the three subgroups (Academy 1, 2, and 3) separately.

12. These statistics refer to the entire, combined sample. Similar results were observed when looking at the three subgroups (Academy 1, 2, and 3) separately. 
13. These statistics refer to the entire, combined sample. Similar results were observed when looking at the three subgroups (Academy 1, 2, and 3) separately.

14. Given that $92.3 \%$ of the present sample reported at least some college experience and $61.2 \%$ had earned college degrees, it is appropriate to compare the present sample with the normative sample of college students. 


\section{References}

Altman, D. G., \& Bland, J. M. (1995). Absence of evidence is not evidence of absence. British Medical Journal, 311, 485.

Aremu, A.O., Pakes, F., and Johnston, L. (2011). The moderating effect of emotional intelligence on the reduction of corruption in the Nigerian Police. Police Practice and Research, 12(3), 195-208.

Background investigation manual: Guidelines for the investigator. (2013). California Commission on Peace Officer Standards and Training.

Bauer, T. N., \& Erdogan, B. (2010). Organizational socialization: The effective onboarding of new employees. In S. Zedeck, H. Aguinis, W. Cascio, M. Gelfand, K. Leung, S. Parker, \& J. Zhou (Eds.). APA Handbook of I/O Psychology, Volume III, (pp. 51-64). Washington, DC: APA Press.

Bennett, R.R. (1984). Becoming blue: A longitudinal study of police recruit occupational socialization. Journal of Police Science and Administration, 12(1), 47-58.

Berg, B.L. (1999). First day at the police academy: Stress-reaction-training as a screening-out technique. Journal of Contemporary Criminal Justice, 6, 89-105.

Berlin, M. (2013). An overview of police training in the United States, historical development, current trends and critical issues: The evidence. In P. Stanislas (ed.). International Perspectives on Police Education and Training. (pp. 23-41). NY: Routledge.

Blumberg, D.M., Griffin, D.A., and Jones, O. (2014). Improving peace officer hiring decisions: An integrated organizational approach. Organizational Cultures: An International Journal, 13(3), 1-19.

Bolander, W., Bonney, L., \& Satornino, C. (2014). Sales education efficacy: Examining the 
relationship between sales education and sales success. Journal Of Marketing Education, $36(2), 169-181$.

Brackett, M.A., Lopes, P.N., Ivcevic, Z., Mayer, J.D., and Salovey, P. (2004). Integrating emotion and cognition: The role of emotional intelligence. In D.Y Dai and R.J. Sternberg (Eds). Motivation, emotion, and cognition: Integrative perspectives on intellectual functioning and development. (pp. 175-194). Mahwah, NJ: Lawrence Erlbaum Associates.

Brackett, M.A., Mayer, J.D., and Warner, R.M. (2004). Emotional intelligence and its relation to everyday behavior. Personality and Individual Differences, 36, 1387-1402.

Brackett, M. A., Rivers, S. E., Shiffman, S., Lerner, N., \& Salovey, P. (2006). Relating emotional abilities to social functioning: A comparison of self-report and performance measures of emotional intelligence. Journal of Personality and Social Psychology, 91(4), 780-795. http://dx.doi.org/10.1037/0022-3514.91.4.780.

Caldero, M.A. and Crank, J.P. (2011). Police ethics: The corruption of noble cause. Burlington, MA: Elsevier, Inc.

Carmeli, A. and Josman, Z.E. (2006). The relationship among emotional intelligence, task performance, and organizational citizenship behaviors. Human Performance, 19(4), 403419.

Caro, C.A. (2011). Predicting state police officer performance in the field training officer program: What can we learn from the cadet's performance in the training academy? American Journal of Criminal Justice, 36, 357-370.

Chappell, A.T. and Lanza-Kaduce, L. (2010). Police academy socialization: Understanding the 
lessons learned in a paramilitary_-bureaucratic organization. Journal of Contemporary Ethnography, 39(2), 187-214.

Charbonneau, D. and Nicol, A.A.M. (2002). Emotional intelligence and prosocial behaviors in adolescents. Psychological Reports, 90, 561-570.

Cherniss, C. (2000). Social and emotional competence in the workplace. In R. Bar-on and J.D.A. Parker (Eds). The handbook of emotional intelligence: Theory, development, assessment, and application at home, school, and in the workplace. (pp. 433-458). San Francisco: Jossey-Bass.

Cohen, J. (1988). Statistical power analysis for the behavioral sciences (2nd ed.). Hillsdale, NJ: Erlbaum.

Conti, N. (2011). Weak links and warrior hearts: A framework for judging self and others in police training. Police Practice and Research, 12(5), 410-423.

Conti, N. and Nolan, J.J. (2005). Policing the platonic cave: Ethics and efficacy in police training. Policing and Society, 15(2), 166-186.

Curtis, G. J., Gouldthorp, B., Thomas, E. F., O'brien, G. M., \& Correia, H. M. (2013). Online academic-integrity mastery training may improve students' awareness of, and attitudes toward, plagiarism. Psychology Learning \& Teaching, 12(3), 282-289.

Dar, O.H., Alam, S., and Lone, Z. A. (2011). Relationship between emotional intelligence and psychological wellbeing of male police personnel. Journal of the Indian Academy of Applied Psychology, 37(1), 47-52.

Day, A.L. and Carroll, S.A. (2004). Using an ability-based measure of emotional intelligence to predict individual performance, group performance, and group citizenship behaviors. Personality and Individual Differences, 36, 1443-1458. 
Dean, G., Bell, P., and Lauchs, M. (2010). Conceptual framework for managing knowledge of police deviance. Policing and Society, 20(2), 204-222.

Ford, R.E. (2003). Saying one thing, meaning another: The role of parables in police training. Police Quarterly, 6(1), 84-100.

Friedman, C.A. (2005) Spiritual survival. Linden, NJ: Compass Books.

Gamarra, A. O. (2012). Call of duty: A question of police integrity. Dissertation Abstracts International Section A, 73, 769.

Garner, R. (2005). Police attitudes: The impact of experience after training. Applied Psychology in Criminal Justice, 1(1), 56-70.

Gaudine, A. and Thorne, L. (2001). Emotion and ethical decision-making in organizations. Journal of Business Ethics, 31, 175-187.

Graves, T.R., Pleban, R.J., Miller, M.L., Branciforte, J.V., Donigian, A.M., Johnson, V., and Matthews, M.D. (2010). Enhancing perception in ethical decision making: A method to address ill-defined training domains. U.S. Army Research Institute for the Behavioral and Social Sciences, Research Report 1932.

Greene, R. L. (2000). The MMPI-2: An interpretive manual (2nd ed.). Boston, MA: Allyn \& Bacon.

Haarr, R.N. (2005). Factors affecting the decision of police recruits to "drop out" of police work. Police Quarterly, 8(4), 431-453.

Haarr, R.N. (2001). The making of a community policing officer: The impact of basic training and occupational socialization on police recruits. Police Quarterly, 4(4), 402-433.

Henson, B., Reyns, B.W., Klahm, C.F., and Frank, J. (2010). Do recruits make good cops? 
Problems predicting and measuring academy and street-level success. Police Quarterly, 13(1), 5-26.

Heffernan, W.C. (1982). Two approaches to police ethics. Criminal Justice Review, 7(28), 2835.

Hirschfeld, R. R., Feild, H. S., \& Bedeian, A. G. (2000). Work alienation as an individualdifference construct for predicting workplace adjustment: A test in two samples. Journal of Applied Social Psychology, 30, 1880-1902.

Jeffreys, H. (1961). Theory of probability (3rd ed.). New York, NY: Oxford University Press.

Johnson, R.A. \& Schlenker, B.R. (2009). Assessing the commitment to ethical principles: Psychometric properties of the Integrity scale. Gainseville, FL: Unpublished manuscript.

Klinger, D.A. (2012). Police training as an instrument of accountability. Saint Louis University Public Law Review, 32(3), 111-121.

Klockars, C.B., Ivkovic, S.K., and Haberfeld, M.R. (2006). Enhancing police integrity. Dordrecht, The Netherlands: Springer.

Klockars, C.B., Ivkovic, S.K., and Haberfeld, M.R. (2004). The contours of police integrity. Thousand Oaks, CA: Sage.

Klockars, C.B., Ivkovic, S.K., Harver, W.E., and Haberfeld, M.R. (2000). The measurement of police integrity. National Institute of Justice Research in Brief, 1-11.

Lopes, P.N., Cote, S., and Salovey, P. (2006). An ability model of emotional intelligence: Implications for assessment and training. In V.U. Druskat, F. Sala, and G. Mount (Eds). Linking emotional intelligence and performance at work (pp. 53-80). Mahway, NJ: Lawrence Erlbaum Associates.

Lopes, P.N., Brackett, M.A., Nezlek, J.B., Schutz, A., Sellin, I., and Salovey, P. (2004). 
Emotional intelligence and social interaction. Personality and Social Psychology Bulletin, 30(8), 1018-1034.

Manzella, L. and West, B. (2003). Emotional intelligence and how it contributes to officer safety. Corrections Today, 65(3), 84-86.

Mayer, J. D., Salovey, P., \& Caruso, D. (2002). The Mayer-Salovey-Caruso Emotional Intelligence Test (MSCEIT), Version 2.0. Toronto, Ontario, Canada: Multi-Health Systems.

Mesmer-Magnus, J., Viswesvaran, C., Deshpande, S.P., and Joseph, J. (2010). Emotional intelligence, individual ethicality, and perceptions that unethical behavior facilitates success. Revista de Psicologia del Trabajo y de las Organizaciones, 26(1), 35-45.

Mesmer-Magnus, J., Viswesvaran, C., Joseph, J., and Deshpande, S.P. (2008). The role of emotional intelligence in integrity and ethics perceptions. In W.J. Zerbe, C. Hartel, and N.M. Ashkanasy (Eds.). Emotions, ethics, and decision-making: Research on Emotion in Organizations, V.4 (pp. 225-239). Bradford, GBR: Emerald Group Publishing.

Miller, L.S. and Braswell, M.C. (1992). Police perceptions of ethical decision-making: The ideal versus the real. American Journal of Police, XI(4), 27-45.

Miller, M.L. and Schlenker, B.R. (2011). Integrity and identity: Moral identity differences and preferred interpersonal reactions. European Journal of Personality, 25, 2-15.

National Institute of Justice (2012). Research on policing. OMB No. 1121-0329. Office of Justice Programs, U.S. Department of Justice.

Paulhus, D. L. (1991). Measurement and control of response bias. In J. P. Robinson, P. R. Shaver, \& L. S. Wrightsman (Eds.), Measures of personality and social psychological attitudes (pp. 17-59). San Diego, CA: Academic Press. 
Paulhus, D. L. (1999). Manual for the Paulhus Deception Scales: BIDR Version 7. Toronto, Ontario, Canada: Multi-Health Systems.

Paulhus, D. L. (2002). Socially desirable responding: The evolution of a construct. In H. Braun, D. N. Jackson, \& D. E. Wiley (Eds.), The role of constructs in psychological and educational measurement (pp. 67-88). Hillsdale, NJ: Erlbaum.

Papazoglou, K. and Anderson, J.P. (2014). A guide to utilizing police training as a tool to promote resilience and improve health outcomes among police officers. Traumatology: An International Journal, 20(2), 103-111.

Prenzler, T. (2009). Police corruption: Preventing misconduct and maintaining integrity. Boca Raton: FL: CRC Press.

Psychological Screening Dimensions for Peace Officer. (2004). California Commission on Peace Officer Standards and Training.

Sadler, M.S., Correll, J., Park, B., and Judd, C.M. (2012). The world is not black and white: Racial bias in the decision to shoot in a multiethnic context. Journal of Social Issues, 68(2), 286-313.

Salovey, P. and Grewal, D. (2005). The science of emotional intelligence. Current Directions in Psychological Science, 14, 281-285.

Schafer, J.A. and Martinelli, T.J. (2008). First-line supervisors' perceptions of police integrity: The measurement of police integrity revisited. Policing: An International Journal of Police Strategies and Management, 31(2), 306-323.

Schlenker, B.R. (2011). Properties of the integrity scale. In-house technical report. University of Florida.

Schlenker, B.R. (2008). Integrity and character: Implications of principled and expedient ethical 
ideologies. Journal of Social and Clinical Psychology, 27(10), 1078-1125.

Schlenker, B. R., Weigold, M. F., \& Schlenker, K. A. (2008). What makes a hero? The impact of integrity on admiration and interpersonal judgment. Journal of Personality, 76(2), 323355.

Schutte, N.S., Schettpelz, E., and Malouff, J.M. (2001). Emotional intelligence and task performance. Imagination, Cognition, and Personality, 20(4), 347-354.

Sellbom, M., Fischler, G.L., and Ben-Porath, Y.S. (2007). Identifying MMPI-2 predictors of police officer integrity and misconduct. Criminal Justice and Behavior, 34(8), 985-1004.

Simons, T., Leroy, H., Collewaert, V., and Masschelein, S. (2014). How leader alignment of words and deeds affects followers: A meta-analysis of behavioral integrity research. Journal of Business Ethics, 1-14.

Smith, M.V. (2010). Police perceptions of integrity: The relationship between emotional intelligence and moral development among police officers. Ph.D. dissertation, Capella University, United States-Minnesota. Retrieved January 18, 2012 from Dissertations and Theses: Full text (Publication No. AAT 3380475).

Stoughton, S. (December 12, 2014) How police training contributes to avoidable deaths. The Atlantic. Retrieved December 20, 2014 from http://www.theatlantic.com/national/archive/2014/12/police-gun-shooting-trainingferguson/383681/?single_page=true

Teasley, C.E. and Wright, L. (1973). The effects of training on police recruit attitudes. Journal of Police Science and Administration, 1(2), 241-248.

Velasquez, M.G. (1998). Business ethics: Concepts and Uses, $4^{\text {th }}$ edition. Upper Saddle River, NJ: Prentice Hall. 
Weiss, P.A., Vivian, J.E., Weiss, W.U., Davis, R.D., and Rostow, C.D. (2013). The MMPI-2 L scale, reporting uncommon virtue, and predicting police performance. Psychological Services, 10(1), 123-130.

White, M.D. (2008). Identifying good cops early: Predicting recruit performance in the academy. Police Quarterly, 11(1), 27-49. 
Table 1. Descriptive Statistics.

\section{N}

Min

\section{Academy 1}

Emotional Intelligence (T1)

143

56.0

71.0

87.0

Social Desirability (T1)

$143 \quad 112.0$

142.0

180.0

$143 \quad 98.0$

138.0

176.0

$143 \quad 56.0$

74.0

88.0

73.0

Raw Integrity Score (T2)

SD Adj. - Integrity Score (T1)

143

SD Adj. - Integrity Score (T2)

143

143

Academy 2

Emotional Intelligence (T1
Social Desirability (T1)
Social Desirability (T2)
Raw Integrity Score (T1)

Raw Integrity Score (T2)

$\begin{array}{cccccccc}87 & 56.0 & 70.0 & 86.0 & 70.7 & 5.8 & .31 & -.32 \\ 87 & 116.0 & 142.0 & 177.0 & 143.8 & 12.3 & .44 & -.06 \\ 87 & 114.0 & 141.0 & 177.0 & 142.6 & 12.6 & .21 & .47 \\ 87 & 55.0 & 72.0 & 90.0 & 72.0 & 7.9 & .08 & -.25 \\ 87 & 56.0 & 72.0 & 87.0 & 72.3 & 7.7 & .23 & -.77\end{array}$




$\begin{array}{lcccccccc}\text { SD Adj. - Integrity Score (T1) } & 87 & 56.3 & 71.3 & 88.6 & 71.7 & 7.2 & .08 & -.11 \\ \text { SD Adj. - Integrity Score (T2) } & 87 & 58.4 & 70.7 & 87.4 & 71.5 & 6.9 & -.75 \\ \text { Academy 3 } & & & & & & & \\ \text { Emotional Intelligence (T1) } & 27 & 59.0 & 70.0 & 81.0 & 69.6 & 6.8 & .01 & -1.39 \\ \text { Social Desirability (T1) } & 27 & 114.0 & 143.0 & 176.0 & 140.8 & 14.4 & .27 & .04 \\ \text { Social Desirability (T2) } & 27 & 113.0 & 136.0 & 172.0 & 138.4 & 15.8 & -45 & -.01 \\ \text { Raw Integrity Score (T1) } & 27 & 61.0 & 71.0 & 83.0 & 71.4 & 6.1 & .23 & -.54 \\ \text { Raw Integrity Score (T2) } & 27 & 57.0 & 72.0 & 86.0 & 73.1 & 7.7 & .10 & -.68 \\ \text { SD Adj. - Integrity Score (T1) } & 27 & 61.5 & 72.1 & 80.9 & 71.9 & 4.7 & -.37 & -.34 \\ \text { SD Adj. - Integrity Score (T2) } & 27 & 61.9 & 74.2 & 83.2 & 73.4 & 5.8 & -.30\end{array}$


Table 2. ANCOVAs: Interaction Effect between Time (Integrity at T1 vs. Integrity at T2) and Emotional Intelligence at T1.

F df $\quad$ p $\quad$ Partial Eta Squared

\begin{tabular}{|c|c|c|c|c|}
\hline \multicolumn{5}{|l|}{ Academy 1} \\
\hline Raw Integrity Score & .31 & $(1,141)$ & .58 & .00 \\
\hline SD Adj. - Integrity Score & .58 & $(1,141)$ & .45 & .00 \\
\hline \multicolumn{5}{|l|}{ Academy 2} \\
\hline Raw Integrity Score & .28 & $(1,85)$ & .59 & .00 \\
\hline SD Adj. - Integrity Score & .88 & $(1,85)$ & .35 & .01 \\
\hline \multicolumn{5}{|l|}{ Academy 3} \\
\hline Raw Integrity Score & 3.43 & $(1,25)$ & .08 & .12 \\
\hline SD Adj. - Integrity Score & 2.83 & $(1,25)$ & .10 & .10 \\
\hline
\end{tabular}


Table 3. Bayesian Statistics: Effects of the Police Academy Training on the Integrity Scores of the Recruits (T1 vs. T2).

\begin{tabular}{|c|c|c|c|c|c|}
\hline & $\mathrm{t}$ & $\mathrm{df}$ & $\mathrm{p}$ & d & JZS B \\
\hline \multicolumn{6}{|l|}{ Academy 1} \\
\hline Raw Integrity Score & 2.22 & 142 & .03 & .19 & 1.36 \\
\hline SD Adj. - Integrity Score & 1.91 & 142 & .06 & .26 & 2.52 \\
\hline \multicolumn{6}{|l|}{ Academy 2} \\
\hline Raw Integrity Score & .45 & 86 & .65 & .05 & 10.70 \\
\hline SD Adj. - Integrity Score & .33 & 86 & .74 & .04 & 11.20 \\
\hline \multicolumn{6}{|l|}{ Academy 3} \\
\hline Raw Integrity Score & 1.33 & 26 & .19 & .26 & 2.93 \\
\hline SD Adj. - Integrity Score & 1.55 & 26 & .13 & .30 & 2.20 \\
\hline
\end{tabular}


Table 4. Percentage of Participants whose Integrity Scores Increased or Decreased "Notably" from T1 to T2.

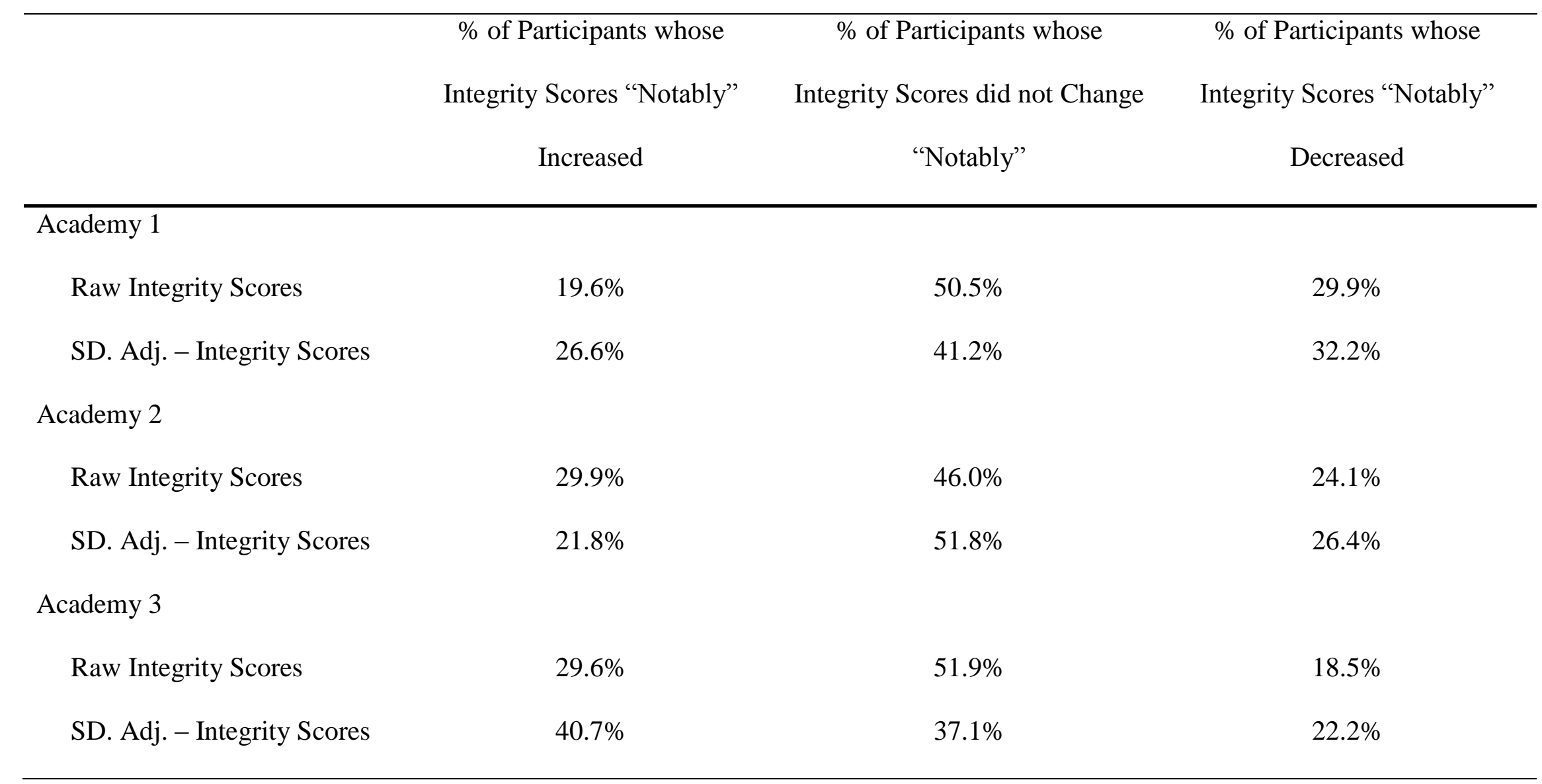

